\title{
Influence of 4 Interfaces in the Assessment of Maximal Respiratory Pressures
}

\author{
Dayane Montemezzo MSc, Danielle Soares Rocha Vieira PhD, Carlos Julio Tierra-Criollo PhD, \\ Raquel Rodrigues Britto PhD, Marcelo Velloso PhD, and Verônica Franco Parreira PhD
}

\begin{abstract}
BACKGROUND: The measurement of maximal respiratory pressure (MRP) is a procedure widely used in clinical practice to evaluate respiratory muscle strength through the maximal inspiratory pressure $\left(\mathbf{P}_{\text {Imax }}\right)$ and maximal expiratory pressure $\left(\mathbf{P}_{\text {Emax }}\right)$. Its clinical applications include diagnostic procedures and evaluating responses to interventions. However, there is great variability in the equipment and measurement procedures. Understanding the impacts of the characteristics of different interfaces can augment the repeatability of this method and help to establish widely applicable predictive equations. The aim of this study was to evaluate the influence of 4 different interfaces on a subject's capacity to generate MRP and the impact of these interfaces on the repeatability of these measurements. METHODS: Fifty healthy subjects (mean \pm SD age $26.36 \pm 4.89 \mathrm{y}$ ) with normal spirometry were evaluated. MRP was measured by a digital manometer connected to 4 interfaces using different combinations of mouthpieces and tubes. The following variables were analyzed: maximum mean pressure, peak pressure, plateau pressure, and plateau variation. Analysis of variance for repeated measures or a Friedman test was used to compare the 4 interfaces, with $P<.008$ after Bonferroni adjustment considered significant. RESULTS: There was no significant difference between the 4 interfaces with respect to maximum mean pressure, peak pressure, plateau pressure, or plateau variation for $P_{\operatorname{Imax}}(P \geq .49)$ or $P_{E \max }(P \geq .11)$, nor did the number of tests performed to fulfill the criteria of repeatability for $P_{I m a x}(P=.69)$ or $P_{E \max }$ $(P=.47)$ differ among the 4 interfaces. CONCLUSIONS: $P_{\text {Imax }}$ and $P_{\text {Emax }}$ values seem not to be influenced by the different interfaces studied, suggesting that patient comfort and availability of interfaces can be considered. Key words: maximal inspiratory pressure; maximal expiratory pressure; muscle strength; mouthpiece. [Respir Care 2012;57(3):392-398. (C) 2012 Daedalus Enterprises]
\end{abstract}

\section{Introduction}

Measuring maximal respiratory pressure (MRP) is a method of investigating the strength of respiratory mus-

\footnotetext{
Ms Montemezzo and Dr Vieira are affiliated with the Rehabilitation Sciences Graduation Program; Dr Tierra-Criollo is affiliated with the Electrical Engineering Department and the Center for Studies and Research in Biomedical Engineering; and Dr Britto, Dr Velloso, and Dr Parreira are affiliated with the Physiotherapy Department and the Laboratory of Assessment and Research in Cardiorespiratory Performance, Universidade Federal de Minas Gerais, Belo Horizonte, Minas Gerais, Brazil.

Dr Parreira presented a version of this paper at the European Respiratory Society Annual Congress, held September 18-22, 2010, in Barcelona, Spain.
}

This research was supported by Pró-Reitoria de Pesquisa da Universidade Federal de Minas Gerais, Fundação de Amparo à Pesquisa do Estado de cles, involving specifically the measurement of both maximal inspiratory pressure $\left(\mathrm{P}_{\mathrm{Imax}}\right)$ and maximal expiratory pressure $\left(\mathrm{P}_{\text {Emax }}\right) . \mathrm{P}_{\text {Imax }}$ and $\mathrm{P}_{\text {Emax }}$ are simple, static, volitional, and effort-dependent tests defined as the respiratory pressure an individual is able to generate from the mouth. The pressure measured during these tests reflects the synergistic action of inspiratory or expiratory muscles. ${ }^{1-3}$

\footnotetext{
Minas Gerais, and Conselho Nacional de Desenvolvimento Científico e Tecnológico. Dayane Montemezzo was partly supported by a scholarship from Coordenação de Aperfeiçoamento de Pessoal de Nível Superior.

Correspondence: Verônica Franco Parreira PhD, Laboratório de Avaliação e Pesquisa em Desempenho Cardiorrespiratório, Universidade Federal de Minas Gerais, Avenida Antônio Carlos, 6627, 31.270-901, Belo Horizonte, Minas Gerais, Brazil. E-mail: veronica.parreira@pq.cnpq.br.
}

DOI: $10.4187 /$ respcare. 01078 
The applicability of MRP tests in the clinical practice of physical therapists and physicians is wide, involving several diagnostic procedures and assessing responses to interventions. ${ }^{4-10} \mathrm{P}_{\text {Imax }}$ is more sensitive to certain clinical disorders, such as situations of muscle weakness, ${ }^{1}$ whereas $\mathrm{P}_{\mathrm{Emax}}$ reflects an important parameter of the ability to cough and expectorate, which are very important for patients with neuromuscular diseases. ${ }^{11}$ These tests were also widely used in research protocols. $., 7,9$

Currently there is great variability in the equipment and procedures used to measure MRP. One possible source of observed differences may be this lack of standardization. ${ }^{1-3,12-17}$ These variations involve the mouthpiece, the tube used to connect the mouthpiece to the manometer, the air leak orifice, the lung volume at which the maneuver is performed, the posture of the individual during the test, the use of a nose clip, the definition of maximum pressure, the duration of the test, the resting time between tests, and the type of manometer (analog or digital). ${ }^{12,15,17-19}$

Recently, in a review of studies assessing MRP in adults, Evans and Whitelaw ${ }^{17}$ noted factors that can influence the measurements, including the interface. However, there is still no formal recommendation regarding the different factors that can influence MRP tests. Consensus exists only on the presence of the air leak orifice (which is $1-2 \mathrm{~mm}$ in diameter ${ }^{1,20}$ ) and the maximum of 5 efforts to achieve repeatability in each $\mathrm{P}_{\operatorname{Imax}}$ and $\mathrm{P}_{\text {Emax }}$ test. ${ }^{2,3}$ Of these 5 efforts, at least 3 should be acceptable and, among these, at least 2 should be reproducible. ${ }^{3}$

Taking into account the relative lack of standardization of equipment and procedures for measuring MRP, many researchers have recommended that they be standardized. ${ }^{1-3,15-17}$ Understanding the influence of different interfaces on the repeatability of the MRP measures can help practitioners and researchers to select the more adequate interface to be used when measuring respiratory muscle strength.

In this context, the main objective of this study was to evaluate the influence of 4 different interfaces that vary with respect to their mouthpieces and tubes on a subject's capacity to generate $\mathrm{P}_{\operatorname{Imax}}$ and $\mathrm{P}_{\text {Emax }}$. Secondarily, the impact of these interfaces on the acceptability and repeatability of the measurements was evaluated.

\section{Methods}

This study was performed at the Laboratory of Assessment and Research in Cardiorespiratory Performance, Physiotherapy Department, Universidade Federal de Minas Gerais, Belo Horizonte, Minas Gerais, Brazil.

\section{Sample}

A convenience sample was recruited from the institution's community. The sample size calculation was based

\section{QUICK LOOK}

\section{Current knowledge}

The measurement of maximal respiratory pressure is a procedure widely used in clinical practice to evaluate respiratory muscle strength. However, there is great variability in the equipment and measurement procedures.

\section{What this paper contributes to our knowledge}

With use of a digital manometer, changing the interface had little effect on the accuracy or reproducibility of the measurement. The best interface for monitoring maximal respiratory pressure may be the interface that provides the greatest patient comfort and acceptance.

on a pilot study with the first 10 subjects who reached the criteria for acceptability and repeatability for MRP tests. ${ }^{3}$ The maximum mean pressure variable was considered for both $\mathrm{P}_{\mathrm{Imax}}$ and $\mathrm{P}_{\mathrm{Emax}}$. For a significance level of .05 $(\alpha=.05)$ and a statistical power of $0.80(\beta=0.20)$, a sample size of 45 subjects was indicated. ${ }^{21}$ Taking into account subject drop-out, a total of 50 subjects were included.

The inclusion criteria were: age between 20 and 50 years $^{22}$; body mass index (BMI) ${ }^{23}$ between 18.5 and $29.9 \mathrm{~kg} / \mathrm{m}^{2}$; no history of or current smoking; no occupational exposure to a risk environment ${ }^{2,24}$; no evident chest deformities ${ }^{3}$; no reported neuromuscular, respiratory or heart disease ${ }^{16}$; no fever in the last 3 weeks prior to the test; no cold or influenza in the week before the test ${ }^{16}$; no use of drugs such as oral corticoids, central nervous system depressants, barbiturates, or muscle-relaxing drugs ${ }^{16}$; and spirometric parameters within the normal range. ${ }^{24}$

The exclusion criteria were: inability to understand or perform the procedures of the research protocol; blood pressure at rest $\geq 180 / 110 \mathrm{~mm} \mathrm{Hg} ; \mathrm{S}_{\mathrm{pO}_{2}}<90 \%$; heart rate $>85 \%$ of maximum predicted..$^{25}$

The study was approved by the ethics committee of the institution (ETIC 556/08), and all subjects gave written informed consent.

\section{Measurement Instruments}

A digital manometer, in which $\mathrm{P}_{\text {Imax }}$ and $\mathrm{P}_{\text {Emax }}$ are measured by pressure transducers, ${ }^{26}$ was used to measure the MRP with 4 different interfaces. This device was developed in a partnership between the Center for Studies and Research in Biomedical Engineering and the Laboratory of Assessment and Research in Cardiorespiratory Performance, Universidade Federal de Minas Gerais. The inter- 


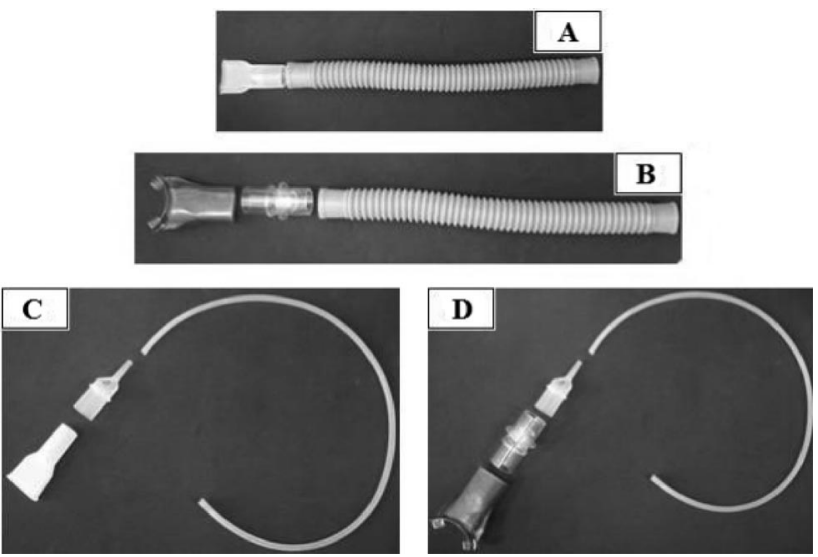

Fig. 1. The 4 interfaces assessed in this study. A: Interface with a $30 \times 2 \mathrm{~cm}$ corrugated plastic tube and a smooth plastic mouthpiece. B: Interface with a $30 \times 2 \mathrm{~cm}$ corrugated plastic tube and a flanged silicone mouthpiece. C: Interface with a $50 \times 0.5 \mathrm{~cm}$ transparent silicone tube and a smooth plastic mouthpiece. D: Interface with a $50 \times 0.5 \mathrm{~cm}$ transparent silicone tube and flanged silicone mouthpiece.

faces were selected based on guidelines ${ }^{1,3}$ and a small survey of Brazilian physiotherapists conducted prior to the study. ${ }^{27}$ The selected interfaces were composed of a tube and a mouthpiece of varying dimensions and materials. Interface A was composed of a corrugated plastic tube $30 \times 2 \mathrm{~cm}$ and a smooth plastic mouthpiece (Hudson RCI, Temecula, California). Interface B was composed of the same tube but with a flanged silicone mouthpiece (ST3, NS Medical Devices, São Paulo, Brazil). Interface C was composed of a transparent silicone tube $50 \times 0.5 \mathrm{~cm}$ and a smooth plastic mouthpiece (Globalmed, Porto Alegre, Brazil). Interface D had the same tube, but with a flanged silicone mouthpiece. All mouthpieces included an air leak orifice of $1.8 \mathrm{~mm} \cdot{ }^{3,20}$ Disposable biological filters were used (Vida Tecnologia Biomédica, São Paulo, SP, Brazil). Figure 1 shows in detail the 4 interfaces used in the study. All parts that composed the interfaces are commercially available, and because the flanged mouthpiece could not be directly connected to the tube, a $2 \times 5 \mathrm{~cm}$ acrylic tube, usually used in noninvasive ventilation circuits, was necessary.

\section{Analyzed Variables}

The following variables were analyzed through the graphic interface of the Manovac 3.0 software of the digital manometer: maximum mean pressure, which is calculated first by finding the peak pressure value and subsequently the pressure is calculated around this point and encompasses the highest values included in a one-second period $^{28}$; peak pressure, which is the highest pressure value obtained during the test ${ }^{28}$; plateau pressure, which refers

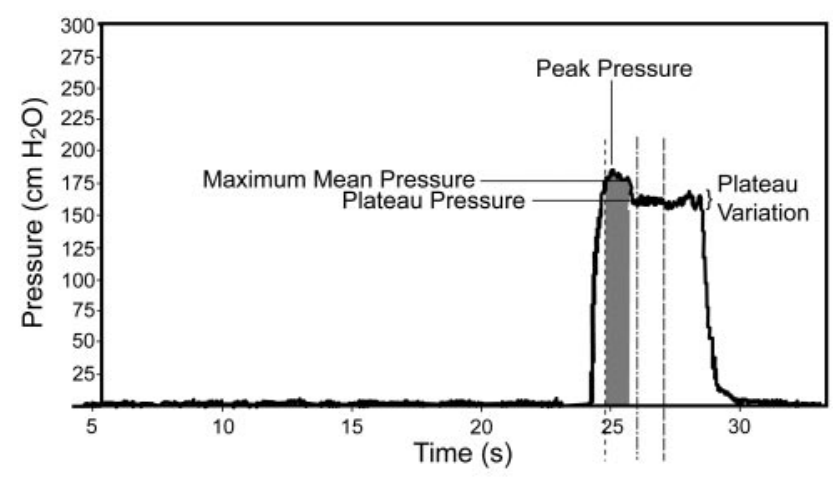

Fig. 2. Example of a maximal expiratory pressure screen display using the Manovac 3.0 graphic interface, with variables identified. The maximum mean pressure, peak pressure, plateau pressure, and plateau variation values obtained during each maneuver are displayed separately. The dotted line indicates the maximum mean pressure onset. The dotted-and-dashed line indicates the plateau pressure onset. The dashed line indicates the plateau pressure end.

to a period of one second ${ }^{19}$ after the peak pressure in which maximum pressure is maintained with less variability ${ }^{26}$; and plateau variation, which indicates the variation of the plateau pressure, for which the maximum acceptable rate was 5\%. Figure 2 shows a screen display obtained during a test, and the 4 variables analyzed in the study are indicated, as well as the onset and end of plateau pressure variable and the onset of maximum mean pressure variable.

\section{Procedures}

Measurements were taken by the same investigator on 2 separate days. On the first day the subjects underwent an interview about their health and physical activity history, and they filled out the Human Activity Profile questionnaire. ${ }^{29,30}$ Subsequently, body mass and height, blood pressure, respiratory rate, heart rate and $\mathrm{S}_{\mathrm{pO}_{2}}$ were measured. A pulmonary function test was performed in accordance with the Brazilian Thoracic Association guideline, ${ }^{24}$ using a spirometer (Vitalograph 2120, Vitalograph, Ennis, Ireland) calibrated prior to the test. Subjects with normal spirometry attended the second day of data collection. Subjects were instructed in advance not to perform strenuous physical activity for 12 hours prior to their MRP test performed on the second day. ${ }^{31}$

On the second day, an electronic randomization of the tests $\left(\mathrm{P}_{\mathrm{Imax}}\right.$ or $\left.\mathrm{P}_{\mathrm{Emax}}\right)$ and of the sequence of interfaces (A, B, C, and D) was performed. The subjects' vital signs (blood pressure, respiratory rate, heart rate, and $\mathrm{S}_{\mathrm{pO}_{2}}$ ) were recorded, they were instructed about the test, and an inducement screen regarding the intensity of effort in the manometer was employed. Following the measurement using the first randomly selected interface and the first 
Table 1. Demographic, Anthropometric, and Spirometric Data Plus Level of Physical Activity for 50 Subjects

\begin{tabular}{lr}
\hline \hline & Mean $\pm \mathrm{SD}$ \\
\hline Age $(\mathrm{y})$ & $26.36 \pm 4.89$ \\
$\mathrm{BMI}\left(\mathrm{kg} / \mathrm{m}^{2}\right)$ & $23.05 \pm 3.06$ \\
$\mathrm{FEV}_{1}(\%$ of predicted $)$ & $93.29 \pm 0.08$ \\
$\mathrm{FVC}(\%$ of predicted $)$ & $90.80 \pm 0.08$ \\
$\mathrm{FEV}_{1} / \mathrm{FVC}(\%$ of predicted) & $102.31 \pm 0.07$ \\
$\mathrm{FEF}_{25-75 \%}(\%$ of predicted) & $92.61 \pm 0.21$ \\
Adjusted Activity Score & $90.16 \pm 4.09$ \\
\hline BMI $=$ body mass index $^{\text {FEF }} 25-75 \%=$ forced expiratory flow in 25-75\% of FVC \\
\hline
\end{tabular}

maximal pressure, there was a 5-minute rest interval. After that, vital signs (blood pressure, respiratory rate, heart rate, and $\mathrm{S}_{\mathrm{pO}_{2}}$ ) were measured. If the vital signs had not returned to baseline parameters, another 5-minute period was given to the subject.

During all the MRP tests the subjects remained seated, received a standardized specific verbal command, and breathed through the mouthpiece and the tube before performing maximal effort. ${ }^{3}$ There was an interval of one minute between each test. ${ }^{3,16,32-34}$ For all tests a nose clip ${ }^{2,16}$ was worn and subjects were instructed to put the mouthpiece between their teeth and hold it firmly with their lips to prevent air leakage. ${ }^{28}$

In the $\mathrm{P}_{\text {Imax }}$ tests the subjects were instructed to perform 3 respiratory cycles and then to expire to residual volume, indicating that moment by elevating their right hand. Simultaneously the examiner closed the occlusion orifice, and at this point the subject generated a maximum inspiratory effort and was encouraged to maintain it for 3 seconds. ${ }^{28}$ In the $\mathrm{P}_{\text {Emax }}$ tests, the subjects were instructed to perform 3 respiratory cycles and then to inspire to total lung capacity, indicating that moment by elevating their right hand. Simultaneously, the examiner closed the occlusion orifice. At that point the subject generated a maximal expiratory effort and was encouraged to maintain it for 3 seconds. ${ }^{28}$ During this test the investigator gently held the subject's cheeks to prevent air from accumulating in the lateral region of the mouth cavity. ${ }^{16}$

The pressure measurement was considered successful when the subject performed at least 3 acceptable tests (ie, no air leakage between the lips or nose clip, and lasting at least one second), and among these, 2 repeatable tests (ie, maximum mean pressure variation less than or equal to $10 \%$ and selection of the highest value observed as long as this value was not the last one obtained).2,3,16 The pressure measurement was not considered acceptable in cases where the criteria for acceptability and repeatability were not achieved in a maximum of 8 tests. ${ }^{24,35}$

The digital manometer was calibrated monthly ${ }^{36}$ using a digital calibrator (PC507, Hotek Technologies, Tacoma,
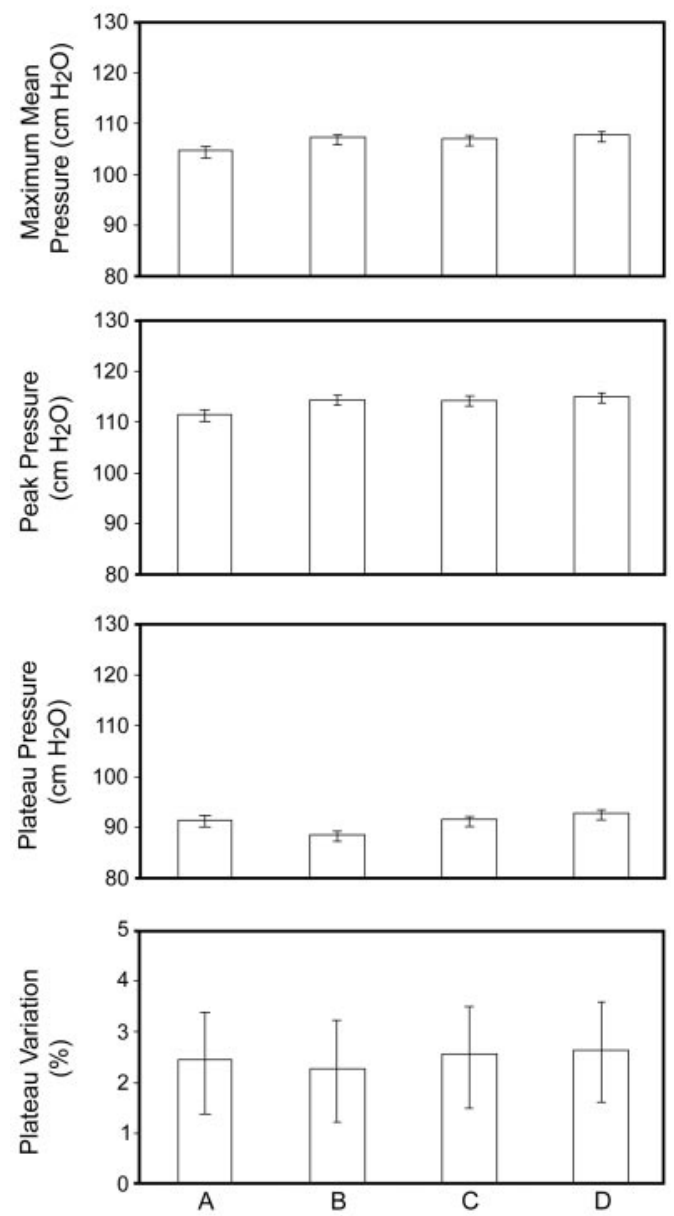

Fig. 3. Comparison of the 4 different interfaces (A, B, C, and D) with respect to variables obtained during maximal inspiratory pressure maneuvers in 50 healthy subjects. Data are shown as mean and standard deviation. None of the differences are significant.

Washington) (accuracy of $0.025 \%$ of full scale) and a duplex pneumatic pump (8111-300, Presys, São Paulo, Brazil) as established by Ferreira et al. ${ }^{26}$ The expanded uncertainty (kappa $=2$ ) of the manometer was $5 \mathrm{~cm} \mathrm{H}_{2} \mathrm{O}$.

\section{Statistical Analysis}

The data are presented as mean and standard deviation. Spirometric parameters and the variables age, BMI, and Human Activity Profile were used to characterize the sample. When analyzing the variables with respect to the MRP measurements, the data distribution was evaluated using the Shapiro-Wilk normality test. When the data were normally distributed, multi-comparisons were performed by analysis of variance for repeated measures, and the Friedman test was used when the data were not distributed normally. The level of significance was set at $P<.008$ after Bonferroni adjustment. ${ }^{37,38}$ The software 

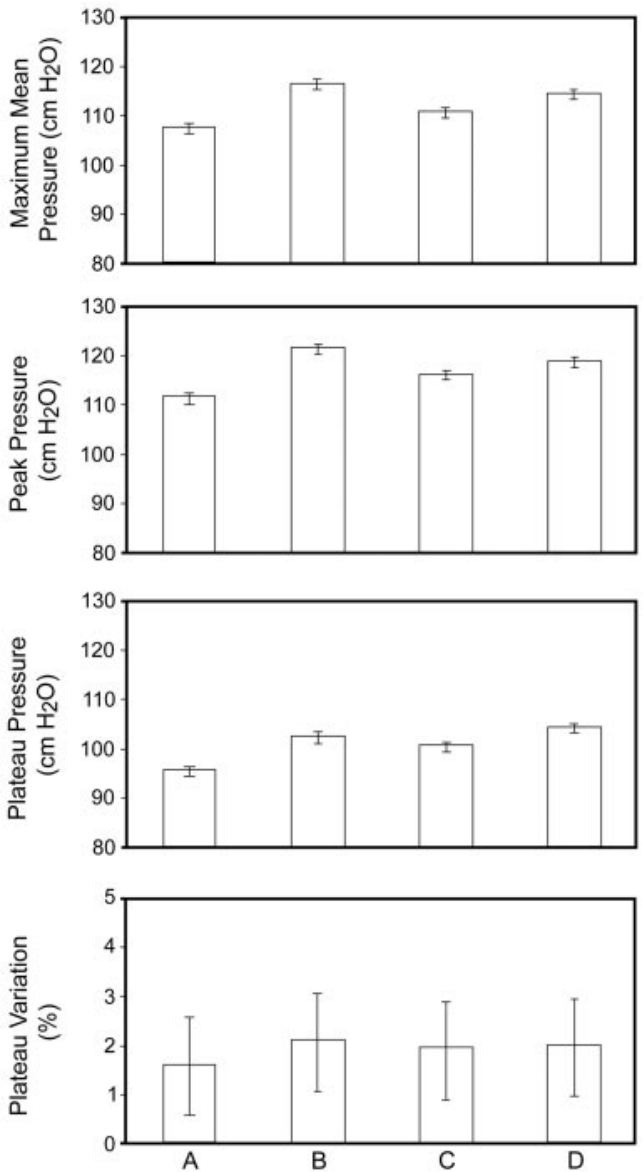

Fig. 4. Comparison of the 4 different interfaces (A, B, C, and D) with respect to variables obtained during maximal expiratory pressure maneuvers in 50 healthy subjects. Data are shown as mean and standard deviation. None of the differences are significant.

SPSS 15.0 (SPSS, Chicago, Illinois) was used for the statistical analysis.

\section{Results}

Sixty subjects were initially selected, 8 of whom had abnormal pulmonary function tests and were not included in the study. Of the 52 subjects included in the study, 2 were excluded due to inability to perform the procedures, despite care taken with respect to previous instructions and motivation during tests. Thus, 50 subjects were studied (26 women and 24 men) and underwent MRP measurements. Interface A was randomly selected to be first for 9 subjects, B for 17, C for 13 and D for 11 .

Table 1 shows the demographic, anthropometric, spirometric, and physical activity level data of the 50 evaluated subjects. Thirty-seven had a BMI within the normal range, 13 were overweight, and all individuals were classified as active.
Table 2. Mean Difference and 95\% Confidence Interval for Maximum Mean Pressure Obtained During $\mathrm{P}_{\mathrm{Imax}}$ and $\mathrm{P}_{\text {Emax }}$ Tests Using Interfaces A, B, C, and D

\begin{tabular}{lcc}
\hline \hline Interfaces & $\begin{array}{c}\left.\mathrm{P}_{\text {Imax }}-\mathrm{Maximum}_{(\mathrm{cm} \mathrm{Mean} \mathrm{Pressure}} \mathrm{O}\right) \\
(\text { mean difference })\end{array}$ & $\begin{array}{c}95 \% \text { CI for Difference } \\
\left(\mathrm{cm} \mathrm{H}_{2} \mathrm{O}\right)\end{array}$ \\
\hline $\mathrm{A}-\mathrm{B}$ & -1.819 & -5.934 to 2.296 \\
$\mathrm{~A}-\mathrm{C}$ & -1.929 & -6.051 to 2.194 \\
$\mathrm{~A}-\mathrm{D}$ & -3.348 & -8.210 to 1.515 \\
$\mathrm{~B}-\mathrm{C}$ & -0.110 & -4.854 to 4.635 \\
$\mathrm{~B}-\mathrm{D}$ & -1.529 & -5.922 to 2.865 \\
$\mathrm{C}-\mathrm{D}$ & -1.419 & -6.671 to 3.833 \\
\hline & -1.958 & -16.410 to 2.689 \\
& -7.093 & -7.896 to 3.979 \\
$\mathrm{~A}-\mathrm{B}$ & $\left(\mathrm{cm} \mathrm{H}_{2} \mathrm{O}\right)($ mean difference) & -15.361 to 1.174 \\
$\mathrm{~A}-\mathrm{C}$ & -6.860 & -4.024 to 13.829 \\
$\mathrm{~A}-\mathrm{D}$ & -0.233 & -7.115 to 6.650 \\
$\mathrm{~B}-\mathrm{C}$ & -5.135 & -12.606 to 2.336 \\
$\mathrm{~B}-\mathrm{D}$ & &
\end{tabular}

$\mathrm{P}_{\mathrm{Imax}}=$ maximal inspiratory pressure

$\mathrm{P}_{\mathrm{Emax}}=$ maximal expiratory pressure

Figure 3 shows the maximum mean pressure, peak pressure, plateau pressure, and plateau variation values for $\mathrm{P}_{\text {Imax }}$, and Figure 4 shows those for $\mathrm{P}_{\text {Emax }}$. When the 4 interfaces were compared, there was no significant difference in any of the variables analyzed for either $\mathrm{P}_{\text {Imax }}$ $(P \geq .49)$ or $\mathrm{P}_{\mathrm{Emax}}(P \geq .11)$.

Table 2 shows the confidence intervals for the primary variable outcome (maximum mean pressure) for both $\mathrm{P}_{\text {Imax }}$ and $\mathrm{P}_{\text {Emax }}$. For all interfaces, the actual repeatability between the 2 highest maximum mean pressure values was lower than $5 \%$ for $\mathrm{P}_{\text {Imax }}$ and $6 \%$ for $\mathrm{P}_{\mathrm{Emax}}$.

Concerning the number of tests required to achieve repeatability with the 4 interfaces, no significant difference was observed among them in the measurement of $\mathrm{P}_{\text {Imax }}$ $(P=.69)$ or $\mathrm{P}_{\text {Emax }}(P=.47)$. Regarding $\mathrm{P}_{\text {Imax }}, 49$ of the 50 subjects met the criteria for repeatability with interfaces $\mathrm{A}, \mathrm{B}$, and $\mathrm{D}$, and 45 met them with interface $\mathrm{C}$. The number of tests was on average $3.80 \pm 1.01$ (A), $3.94 \pm 1.34$ (B), $4.24 \pm 1.53$ (C), and $3.96 \pm 1.29$ (D). Regarding $\mathrm{P}_{\mathrm{Emax}}, 48$ of the 50 subjects met the criteria for repeatability with interface $A, 47$ met them with $B$ and $C$, and 50 met them with $\mathrm{D}$. The number of tests was $4.24 \pm 1.30(\mathrm{~A}), 4.47 \pm 1.32(\mathrm{~B}), 4.50 \pm 1.44(\mathrm{C})$, and $4.14 \pm 1.21(\mathrm{D})$.

\section{Discussion}

The main findings of this study were:

- The values obtained for the MRP $\left(\mathrm{P}_{I \max }\right.$ and $\left.\mathrm{P}_{\text {Emax }}\right)$ parameters of maximum mean pressure, peak pressure, plateau pressure, and plateau variation did not differ significantly between the 4 different interfaces. 


\section{Influence of 4 Interfaces in the Assessment of MaXimal Respiratory Pressures}

- There was no significant difference among the 4 interfaces studied in the number of tests needed to achieve the repeatability criteria in the measurement of MRP $\left(\mathrm{P}_{\text {Imax }}\right.$ and $\left.\mathrm{P}_{\mathrm{Emax}}\right)$.

To our knowledge, only 2 studies have compared the influence of different mouthpieces on the MRP measurement. Koulouris et $\mathrm{al}^{32}$ compared 2 types of mouthpieces (flanged-type and rubber tube) in 21 healthy subjects and 40 patients divided into 2 subgroups, according to normal values $^{39}$ of $\mathrm{P}_{\text {Imax }}$. In cases where the inspiratory muscle strength was considered to be normal, significantly higher values of both $\mathrm{P}_{\text {Imax }}$ and $\mathrm{P}_{\text {Emax }}$ were observed with the tubular mouthpiece. These authors suggested that the shape, size, and way of using the mouthpiece are factors that can interfere in the measurement of MRP, because they require activation and coordination of different groups of muscles according to the characteristics of the mouthpiece. This idea is shared by other authors. ${ }^{1-3,12-17}$

Tully et $\mathrm{al}^{40}$ studied 50 male patients with spinal cord injuries and observed significantly lower $\mathrm{P}_{\text {Emax }}$ values when measurements were made with the flanged mouthpiece, compared with the tube-style one. In the present study, which included only healthy subjects, no significant differences were observed among the interfaces evaluated. Patients with muscular injury or respiratory disease may show changes in respiratory mechanics, which could account for the findings of Tully et al. ${ }^{40}$

In our study it was not possible to include the tubular plastic, cardboard mouthpiece, or circular rubber used by Black and Hyatt, ${ }^{39}$ and this could be considered a limitation. In order to ensure the acceptability of the test, the recommendation for the use of the flanged mouthpiece published in 2002 by the American Thoracic Society and European Respiratory Society, ${ }^{1}$ and reinforced by Evans and Whitelaw, ${ }^{17}$ was adopted. Another aspect to be considered is that the results of the present study cannot be generalized to children, the elderly, or unhealthy people.

Regarding the number of tests needed to achieve the criteria of acceptability and repeatability, the results of this study support the recommendations of the American Thoracic Society and European Respiratory Society ${ }^{1}$ and the Brazilian Thoracic Association, ${ }^{3}$ which were recently reiterated in a review on the topic. ${ }^{17}$ The results of this study showed that the subjects reached these criteria with approximately 4 tests $(3.80-4.50)$ for both $\mathrm{P}_{\mathrm{Imax}}$ and $\mathrm{P}_{\mathrm{Emax}}$, with no significant difference between the evaluated interfaces.

This was the first clinical study performed with this digital manometer, which allows connection with a large number of available tubes and mouthpieces. Moreover, the software Manovac 3.0 provides an easy to use graphic interface allowing the user to register the subject's data, select the type of MRP test, visualize a graphical display of the test in real time, and access and store information from multiple tests. The analysis of values from curves displayed in the manometer represents an improvement in the assessment of respiratory pressure and may positively impact treatment decisions. The manometer also provides other interesting variables besides peak pressure and maximal mean pressure, including the plateau pressure and plateau variation. This last variable can provide relevant information regarding one-second time periods with less variability in the MRP curves. To the best of our knowledge, these variables have not been described, and future studies are needed to determine their role in MRP tests.

\section{Conclusions}

In conclusion, when $\mathrm{P}_{\text {Imax }}$ and $\mathrm{P}_{\text {Emax }}$ were measured with 4 different interfaces, no significant difference was found in the values obtained for maximum mean pressure, peak pressure, plateau pressure, or plateau variation, nor was there a difference in the number of tests performed to meet the repeatability criteria. Thus, it might be interesting to consider the comfort reported by subjects who undergo MRP measurements. The results of the present study can be used as a framework for future studies investigating the influence of mouthpieces on respiratory muscle pressure in different patient populations.

\section{REFERENCES}

1. Green M, Road J, Sieck GC, Similowski T. American Thoracic Society/European Respiratory Society. Statement on respiratory muscle testing: tests of respiratory muscle strength. Am J Respir Crit Care Med 2002;166(4):528-547.

2. Neder JA, Andreoni S, Lerario MC, Nery LE. Reference values for lung function tests II. Maximal respiratory pressures and voluntary ventilation. Braz J Med Biol Res 1999;32(6):719-727.

3. de Souza RB; Sociedade Brasileira de Pneumologia e Tisiologia. Diretrizes para Testes de Função Pulmonar: Pressões respiratórias estáticas máximas. J Bras Pneumol 2002;28(Suppl 3):S155-S165. Article in Portuguese.

4. Fregonezi GA, Resqueti VR, Guell R, Pradas J, Casan P. Effects of 8-week, interval-based inspiratory muscle training and breathing retraining in patients with generalized myasthenia gravis. Chest 2005; 128(3):1524-1530

5. Nicot F, Hart N, Forin V, Boule M, Clement A, Polkey MI, et al. Respiratory muscle testing: a valuable tool for children with neuromuscular disorders. Am J Respir Crit Care Med 2006;174(1):67-74.

6. Terzano C, Ceccarelli D, Conti V, Graziani E, Ricci A, Petroianni A. Maximal respiratory static pressures in patients with different stages of COPD severity. Respir Res 2008;9:8.

7. Forti E, Ike D, Barbalho-Moulim M, Rasera Jr I, Costa D. Effects of chest physiotherapy on the respiratory function of postoperative gastroplasty patients. Clinics 2009;64(7):683-689.

8. Puente-Maestu L, Abad YM, Pedraza F, Sanchez G, Stringer WW. A controlled trial of the effects of leg training on breathing pattern and dynamic hyperinflation in severe COPD. Lung 2006;184(3): 159-167.

9. Dall'Ago P, Chiappa GR, Guths H, Stein R, Ribeiro JP. Inspiratory muscle training in patients with heart failure and inspiratory muscle weakness: a randomized trial. J Am Coll Cardiol 2006;47(4): 757-763. 


\section{Influence of 4 Interfaces in the Assessment of MaXimal Respiratory Pressures}

10. Battaglia E, Fulgenzi A, Ferrero ME. Rationale of the combined use of inspiratory and expiratory devices in improving maximal inspiratory pressure and maximal expiratory pressure of patients with chronic obstructive pulmonary disease. Arch Phys Med Rehabil 2009;90(6): 913-918.

11. Enright PL, Kronmal RA, Manolio TA, Schenker MB, Hyatt RE. Respiratory muscle strength in the elderly. Correlates and reference values. Cardiovascular Health Study Research Group. Am J Respir Crit Care Med 1994;149(2 Pt 1):430-438.

12. Smyth RJ, Chapman KR, Rebuck AS. Maximal inspiratory and expiratory pressures in adolescents. Normal values. Chest 1984;86(4): 568-572.

13. Harik-Khan RI, Wise RA, Fozard JL. Determinants of maximal inspiratory pressure. The Baltimore Longitudinal Study of Aging. Am J Respir Crit Care Med 1998;158(5 Pt 1):1459-1464.

14. Fauroux B. Respiratory muscle testing in children. Paediatr Respir Rev 2003;4(3):243-249.

15. Brunetto AF, Alves LA. Comparação entre os valores de pico e sustentado das pressões respiratórias máximas em indivíduos saudáveis e pacientes portadores de pneumopatia crônica. J Bras Pneumol 2003;29(4):208-212. Article in Portuguese.

16. Parreira VF, França DC, Zampa CC, Fonseca MM, Tomich GM, Britto RR. Maximal respiratory pressures: actual and predicted values in healthy subjects. Rev Bras Fisioter 2007;11(5):361-368.

17. Evans JA, Whitelaw WA. The assessment of maximal respiratory mouth pressures in adults. Respir Care 2009;54(10):1348-1359.

18. Chen HI, Kuo CS. Relationship between respiratory muscle function and age, sex, and other factors. J Appl Physiol 1989;66(2):943-948.

19. Windisch W, Hennings E, Sorichter S, Hamm H, Criee CP. Peak or plateau maximal inspiratory mouth pressure: which is best? Eur Respir J 2004;23(5):708-713.

20. Mayos M, Giner J, Casan P, Sanchis J. Measurement of maximal static respiratory pressures at the mouth with different air leaks. Chest 1991;100(2):364-366.

21. Portney LG, Watkins MP. Sampling. In: Portney LG, Watkins MP, editors. Foundations of Clinical Research Applications to Pratice. New Jersey: Pearson Prentice Hall;2009:142-159.

22. Britto RR, Zampa CC, Oliveira TA, Prado LF, Parreira VF. Effects of the aging process on respiratory function. Gerontology 2009; 55(5):505-510.

23. World Health Organization. Global database on body mass index (BMI). http://www.who.int/nutrition/databases/bmi/en. Accessed December 30, 2011.

24. Pereira CAC, Sato T, Rodrigues SC. New reference values for forced spirometry in white adults in Brazil. J Bras Pneumol 2007;33(4): 397-406.

25. Arena R, Myers J, Guazzi M. The clinical importance of cardiopulmonary exercise testing and aerobic training in patients with heart failure. Rev Bras Fisioter 2008;12(2):75-87.

26. Ferreira JL, Tierra-Criollo CJ, Pereira NC, Oliveira Júnior M, Vasconcelos FH, Parreira VF. Maximum respiratory pressure measuring system: calibration and evaluation of uncertainty. SBA Controle Automação 2010;21(6):588-597.

27. Montemezzo D, Velloso M, Britto RR, Parreira VF. Pressões respiratórias máximas: equipamentos e procedimentos usados por fisioterapeutas brasileiros. Fisioterapia e Pesquisa 2010;17(2):147-152. Article in Portuguese.

28. Hamnegard CH, Wragg S, Kyroussis D, Aquilina R, Moxham J, Green M. Portable measurement of maximum mouth pressures. Eur Respir J 1994;7(2):398-401.

29. Fix AJ, Daughton DM. Human Activity Profile: professional manual. Nebraska: Psychological Assessment Resources; 1988:1-25.

30. Souza AC, Magalhaes LC, Teixeira-Salmela LF. Cross-cultural adaptation and analysis of the psychometric properties in the Brazilian version of the Human Activity Profile. Cad Saude Publica 2006; 22(12):2623-2636.

31. Neder JA, Andreoni S, Castelo-Filho A, Nery LE. Reference values for lung function tests. I. Static volumes. Braz J Med Biol Res 1999;32(6):703-717.

32. Koulouris N, Mulvey DA, Laroche CM, Green M, Moxham J. Comparison of two different mouthpieces for the measurement of PImax and PEmax in normal and weak subjects. Eur Respir J 1988;1(9): 863-867.

33. Fiz JA, Carreres A, Rosell A, Montserrat JM, Ruiz J, Morera JM. Measurement of maximal expiratory pressure: effect of holding the lips. Thorax 1992;47(11):961-963.

34. Fiore Júnior JF, Paisani DM, Franceschini J, Alves LA, Faresin SM. Maximal respiratory pressures and vital capacity: comparison between mouthpiece and face-mask evaluation methods. J Bras Pneumol 2004;30(6):515-520.

35. Fiz JA, Montserrat JM, Picado C, Plaza V, Gusti-Vidal A. How many manoeuvres should be done to measure maximal inspiratory mouth pressure in patients with chronic airflow obstruction? Thorax 1989;44(5):419-421.

36. Wohlgemuth M, Van Der Kooi EL, Hendriks JC, Padberg GW, Folgering HT. Face mask spirometry and respiratory pressures in normal subjects. Eur Respir J 2003;22(6):1001-1006.

37. Munro BH. Selected nonparametric techniques. In: Munro BH, editor. Statistical methods for health care research. Philadelphia: Lippincott Williams \& Wilkins; 2005:109-136.

38. Portney LG, Watkins MP. Comparing more than two means: analysis of variance. In: Portney LG, Watkins MP, editors. Foundations of clinical research applications to practice. New Jersey: Pearson/ Prentice Hall; 2009:451-477.

39. Black LF, Hyatt RE. Maximal respiratory pressures: normal values and relationship to age and sex. Am Rev Respir Dis 1969;99(5): 696-702.

40. Tully K, Koke K, Garshick E, Lieberman SL, Tun CG, Brown R. Maximal expiratory pressures in spinal cord injury using two mouthpieces. Chest 1997;112(1):113-116.

This article is approved for Continuing Respiratory Care Education credit. For information and to obtain your CRCE

(free to AARC members) visit www.RCJournal.com

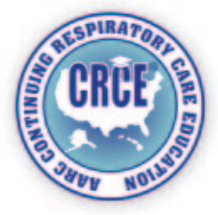

